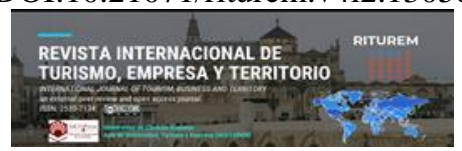

Cita bibliográfica: Muñoz Castillo, J.A. (2020). Potencialidades turístico-recreativas del patrimonio nuclear del sur de España: una vision geográfica. Revista Internacional de Turismo, Empresa y Territorio, 4 (2), 52-67. https://doi.org/10.21071/riturem.v4i2.13058

\title{
Potencialidades turístico-recreativas del patrimonio nuclear del sur de España: una visión geográfica
}

\author{
Tourist-recreational potentialities of the nuclear heritage of southern Spain: a \\ geographical vision
}

\author{
Juan Antonio Muñoz Castillo ${ }^{1 *}$
}

\begin{abstract}
Resumen
En este trabajo se analiza desde una óptica geográfica el patrimonio nuclear del Sur de España que se concentra en un conjunto de territorios que, vinculados a la energía nuclear en distintas facetas de nuestra historia reciente, presentan no pocas posibilidades como soporte de nuevos productos turísticorecreativos, los cuales se intentan identificar en esta investigación. Se trata de territorios con fuerte éxodo rural y despoblación, importante crisis de sus actividades económicas tradicionales y lexcesiva dependencia de los subsidios y ayudas sociales públicos, a lo que se suma el desmantelamiento de sus instalaciones vinculadas a la energía nuclear y/o la extracción de uranio. Asimismo, sufren el lastre que para la imagen de sus territorios representa su "pasado nuclear", que ha frenado o suspendido proyectos que podrían haber servido para aliviar su estado actual de fuerte depresión socioeconómica y emprender algunas iniciativas de desarrollo sostenible. Por tanto, en este estudio se pretenden vislumbrar las posibilidades de generación de actividades y productos turísticos-recreativos, de educación ambiental, culturales o de turismo rural y turismo deportivo de naturaleza que puedan insertar adecuadamente estas áreas en los mercados turísticos nacionales e internacionales, contribuyendo así a buscar fórmulas complementarias de desarrollo y generación de ingresos para las poblaciones rurales que las integran.
\end{abstract}

Palabras clave: patrimonio nuclear, turismo rural, potencialidades turísticas, sur de España.

\begin{abstract}
This paper analyzes with a geographical optics the nuclear heritage of southern Spain, which is concentrated in a set of territories that, linked to nuclear energy in different facets, present not a few possibilities for tourism development, which are attempted to identify in this research. These are territories whose strong rural exodus and its consequent depopulation, added to the dismantling of nuclear or uranium extraction activities and the excessive dependence on subsidies and public social assistance, along with the ballast that for the image of these territories, it represents their "nuclear past", they have halted or suspended projects, that, of course, well focused, could have served to alleviate their current state of strong socio-economic depression and undertake some initiatives for sustainable development. Therefore, this study intends to glimpse the possibilities of generating activities and tourist-recreational products, environmental education, cultural and rural tourism and nature sports tourism that can properly insert these areas into national and international tourist markets,
\end{abstract}

1 Departamento de Geografía e Historia. I.E.S. "Luis de Góngora", Córdoba, España. Email: drjuanmunoz75@gmail.com* Autor para la correspondencia 
contributing thus to look for complementary formulas of development and generation of income for the rural populations that integrate them.

Keywords: nuclear heritage, rural tourism, tourist potentialities, Southern Spain.

\section{Introducción y contextualización geográfica}

El presente trabajo es un resultado parcial del proyecto de tesis doctoral, titulado "Patrimonio Nuclear del Sur de España, un estudio geográfico", de próxima defensa en este año 2020, tras una dilatada trayectoria de investigación de muchos años sobre este tema.

Fundamentalmente esta investigación se ha centrado en el marco geográfico de áreas rurales de interior del sur de España con municipios que, o bien han albergado centrales nucleares hoy en desuso, o en todo caso conservan elementos patrimoniales de entidad relacionados con estas instalaciones y algunas actividades que las sustentaban como la extracción y transformación del uranio y los depósitos y cementerios de residuos radiactivos.

En todos los casos analizados se trata de municipios que han sufrido un proceso relativamente reciente de desmantelamiento de sus actividades e instalaciones principales vinculadas a la energía nuclear, una vez han acabado su vida útil, de manera que se han quedado generalmente sin su principal fuente de ocupación laboral y de actividad económica. En consecuencia, se han analizado en este estudio todos aquellos factores geográficos, socioeconómicos y socioculturales que puedan plantear en estos territorios cambios de usos para facilitar nuevas alternativas de desarrollo económico y, en este caso concreto que analizamos, desde la vertiente turístico-recreativa y de ocio.

La presente investigación propone, en definitiva, una reutilización y una puesta en valor turístico-recreativo no sólo de las estructuras e instalaciones ya en desuso o infrautilizadas, sino también de las áreas limítrofes con capacidad suficiente para constituirse en espacios de ocio de oportunidad, potenciando actividades tradicionales ya existentes desde antiguo como la caza y la pesca, el senderismo o el montañismo, como también otras relacionadas con el turismo rural, el turismo gastronómico o el turismo deportivo-activo de naturaleza, cuyo desarrollo se pudiera haber afectado por la imagen negativa de estas zonas para el turismo durante el transcurso de sus actividades ligadas a la energía nuclear.

Partimos, para ello, de la hipótesis inicial de que estas zonas tienen no pocas potencialidades turístico-recreativas preexistentes a la actividad nuclear pero que no se han desarrollado por los condicionamientos derivados de la misma, pero que una vez desmantelada aquélla pueden reactivarse y, al mismo tiempo, complementarse con la reutilización de antiguas instalaciones, estructuras y entornos nucleares o radiactivos en diversos sectores económicos y ambientales que aporten valor añadido (empleo de calidad, captación de talento, ecología, salud, ocio, etc.), y particularmente en el ámbito del turismo rural, minero-industrial, cultural y de naturaleza.

Asimismo, consideramos como otro punto de partida, refrendado por el levantamiento de una exhaustiva información territorial in situ, la existencia en estos territorios de un patrimonio singular y diferencial, muy mal estudiado, que, en cualquier caso, necesita de un análisis y tratamiento específico como nuevo instrumento potencial de desarrollo para unos lugares con una serie de características comunes de depresión socioeconómica y que, más allá de la invisibilidad y ocultación de sus realidades territoriales como periferias dependientes y marginadas por las instancias públicas, merecen mucho más de atención de la que tienen.

El estudio se centra, en concreto, en el territorio de las antiguas minas de uranio de El Cabril y área del Cementerio de Residuos Nucleares de Sierra Albarrana (Córdoba), minas de uranio del municipio de Cardeña (también en Córdoba, en la comarca de Los Pedroches 
Orientales), el área de la Virgen de la Cabeza (Jaén), en la Sierra de Andújar, la zona de La HabaLobo-Pedregal-Marilozana (Badajoz), el territorio afectado por el accidente aéreo-nuclear de Palomares y su Sierra Almagrera (Almería) y el entorno de Valdecaballeros, también en Badajoz (Figura 1).

En todos los casos, encontramos una característica común y relevante desde el punto de vista geográfico como es su situación aledaña o cercana a espacios naturales protegidos o áreas de interés naturalístico, paisajístico y ambiental, con lo que ello supone de potencialidad territorial para el fomento de actividades de turismo de naturaleza, aún cuando hasta ahora y en buena medida no hayan pasado de plasmarse en proyectos de un calado bastante limitado y unos resultados más bien escasos en cuanto a generación de rentas complementarias en estas comarcas, salvo algunas muy respetables excepciones que confirman la norma habitual como son los casos del entorno de Palomares, y en mucha menor medida, la Sierra de Andújar.

Figura 1

Localización de las zonas de estudio en el Mapa Geológico de España.

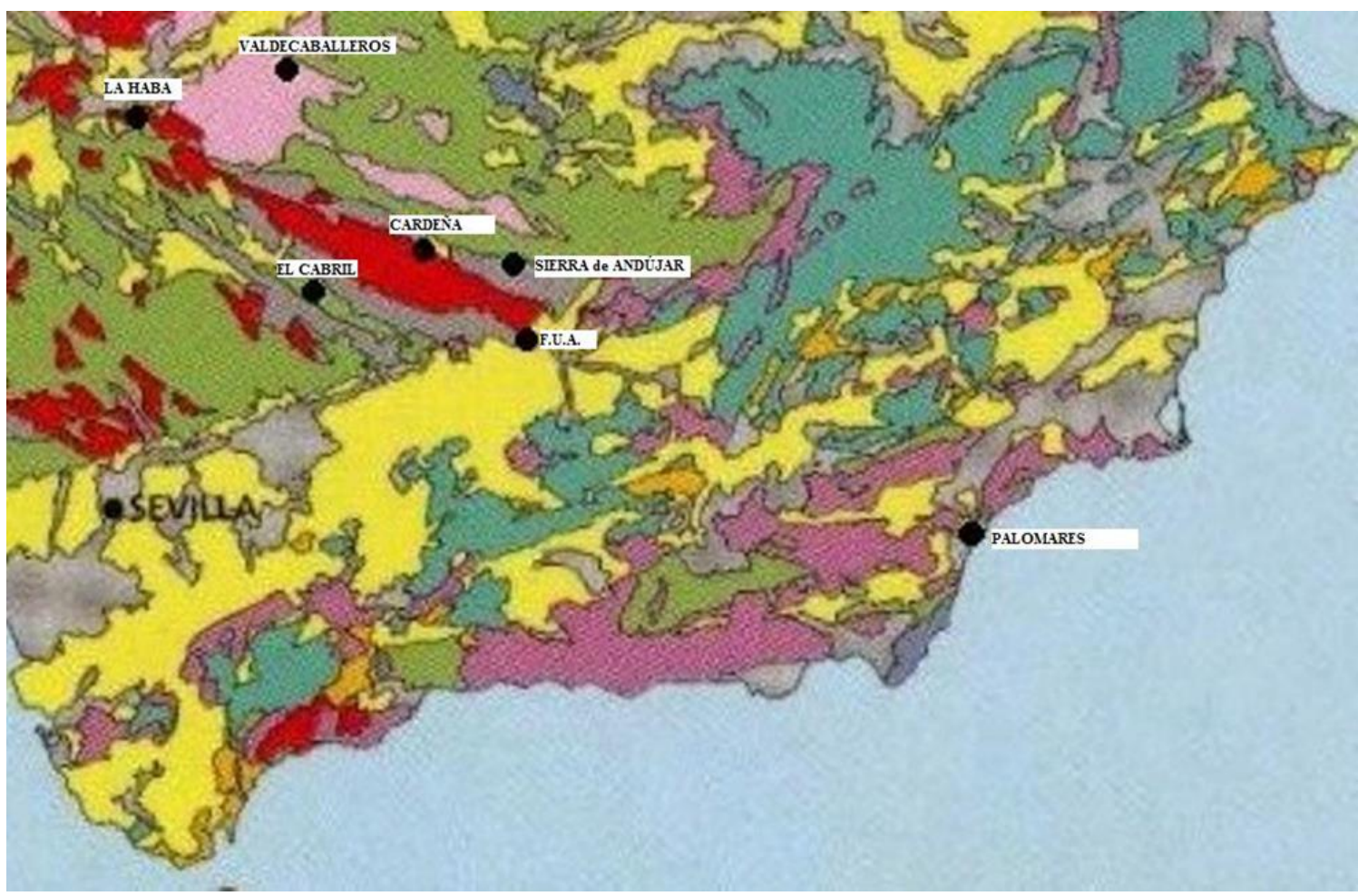

Fuente: Mapa Geológico de España E: 1:10.000 (IGME). Adaptación propia.

\section{Metodología y herramientas de trabajo}

La metodología utilizada en este trabajo ha sido de carácter cualitativo y fundamentalmente descriptiva y exploratoria, basada en un exhaustivo trabajo de campo, en la observación participante y en el establecimiento de contactos y entrevistas en profundidad tanto con agentes cualificados de los territorios seleccionados (stakeholders) como con antiguos trabajadores o habitantes que han sobrevivido sobre el terreno a los cuantiosos avatares vividos por estos lugares tan concretos. La temporalización sobre el desarrollo de los distintos periodos de 
recogida de la información ha estado condicionada por la disponibilidad del autor en los últimos tres años de trabajo.

Se ha partido del levantamiento de numerosa información de carácter geográfico que nos ha servido, en primer término, para identificar los recursos territoriales de mayor potencialidad de aprovechamiento turístico-recreativo de manera sostenible con las condiciones paisajísticas y ambientales y socioculturales de estas áreas. Complementariamente se ha realizado una exploración específica de diversas fuentes secundarias existentes para abordar el diagnóstico territorial, ciertamente escasas, por lo que el trabajo de campo y la observación participante en el seno de las poblaciones locales ha resultado fundamental, así como la utilización de algunos informes internos y literatura gris-y en general, muy poco o nada difundida- de las entidades relacionadas con las instalaciones y estructuras del patrimonio nuclear español .

Respecto al estado de la cuestión sobre el tema central del patrimonio nuclear español, lo cierto es que apenas existen estudios específicos, como consecuencia de que ha sido una temática muy poco tratada, que requiere de conocimientos multidisciplinares, pese a no haber hasta ahora casi ningún interés por parte de numerosas disciplinas científicas hasta la fecha, más allá de algunos trabajos clásicos y algún otro de reciente aparición. Por tanto, los estudios de caso que hemos realizado sobre estos territorios del Sur de España unidos por su relación con la industria nuclear, nos han servido tanto para plantear hipótesis de partida como también para determinar la metodología aplicable de investigación sobre la marcha y plantear unas teorías y conclusiones generales y aplicables a la mayoría de lugares con elementos patrimoniales similares. Como, por otra parte, es el conjunto que integra el objeto de estudio.

\section{Resultados y discusión por territorios analizados}

\subsection{La Sierra de Andújar y el entorno de la Virgen de la Cabeza.}

La Sierra de Andújar, parcialmente convertida en Parque Natural en aplicación de la Ley 2/1989 de Espacios Naturales Protegidos de Andalucía, fue uno de los primeros espacios naturales protegidos de Andalucía. No en vano, el parque, con una superficie actual de 74.474 hectáreas, se extiende no sólo por la mayor parte de la zona serrana del término municipal de Andújar, sino también por un sector nada despreciable de las mismas zonas de los términos municipales de Marmolejo, Villanueva de la Reina y Baños de la Encina.

La hostelería tiene su relativa importancia en Andújar, no sólo por el volumen de su población, que se acerca a los cuarenta mil habitantes, casi en su totalidad en la capital municipal y los poblados de colonización que la rodean, sino también por su propia dinámica interna (ferias, romería de la Cabeza, monterías, otras actividades paralelas o asociadas a las antedichas celebraciones). La agrociudad andujareña es, en sí misma, cabeza de una comarca nada pequeña, con una importancia comercial, logística y de servicios nada despreciable en el conjunto de la provincia de Jaén. 


\section{Figura 2}

Santuario de la Virgen de la Cabeza. Cuesta imaginar que desde allí se podían ver hasta hace no tantos años los calveros y cortas de las minas de uranio.

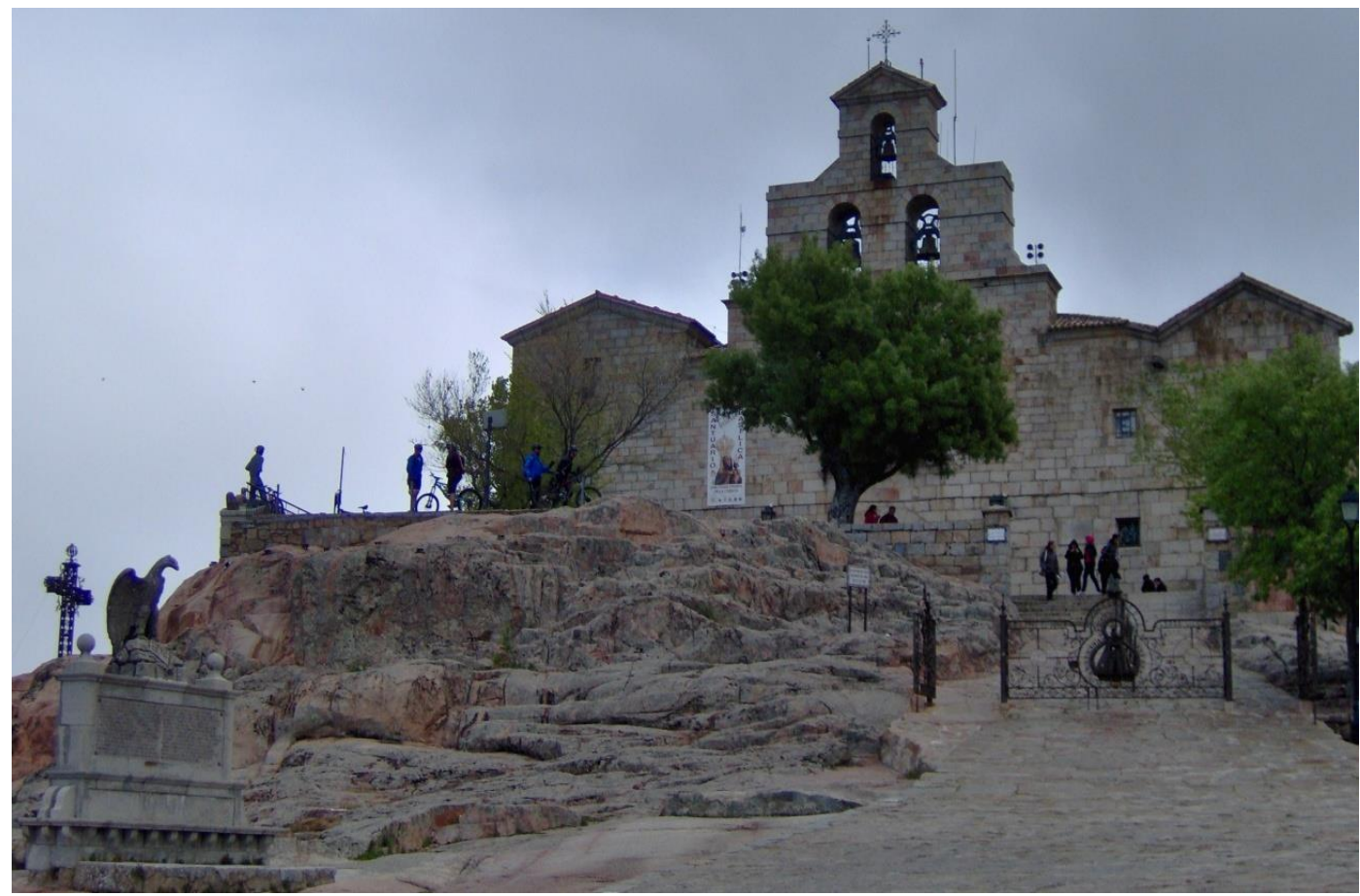

Fuente: Fotografía del autor (hacia 2012).

En vista del éxito, al menos a priori, de las labores llevadas a cabo con el derribo, desmantelamiento y sellado de la antigua Fábrica de Uranio de Andújar (FUA), la Empresa Nacional de Residuos Radiactivos, S.A. (ENRESA) emprendió a mediados de los años noventa del pasado siglo el proceso para el sellado y restauración paisajística de las antiguas minas de uranio. Y entre éstas, se encontraban los yacimientos iliturgitanos del entorno norte-noroeste del Santuario de Nuestra Señora de la Cabeza. A saber, Navalasno, Montealegre, Raso de los Machos y La Virgen. Todos habían cesado en sus actividades en 1971. Dieciocho años más tarde, por cuenta de la Ley 2/1989 de "Espacios Naturales Protegidos de Andalucía", quedaron incluidos dentro de los límites del Parque Natural de las Sierras de Andújar. No fue esta realidad óbice para que los ingenieros de ENRESA decidieran acometer el proyecto de restauración paisajística de las antiguas minas de uranio dependientes en su momento de la JEN-organismo del que se originó en parte la propia ENRESA-, si bien con más de un cuarto de siglo de retraso en la fecha en la que deberían haberse acometido apenas cesada la explotación.

Es innegable el potencial turístico de la sierra y la propia localidad de Andújar, si bien con un dimorfismo palpable, porque si bien hay una notable actividad cinegética y ganadera en las fincas de la sierra, tanto dentro como fuera del Parque Natural, no hay una mayor diversificación productiva por la existencia de una demanda turístico-recreativa aún en ciernes, pese a que hay algunas tradiciones y recursos intangibles -como la Romería de la Virgen de la Cabeza, la mayor de Andalucía a excepción de la del Rocío- que tienen resonancia más allá de las fronteras regionales (Figura 2). 
En conclusión, las potencialidades turísticas de la sierra de Andújar pasan por una mayor visibilización del conjunto de productos ofrecidos, pues, por más esfuerzos que se han hecho, parece ser que están necesitados de un acicate que asiente una promoción definitiva a través de una nueva y cualificada imagen y marca turística.

En cuanto a la parcela ocupada por la antigua FUA, nos encontramos con un elemento tan polémico y tan difícil de reconsiderar que se escapa de los ámbitos y objetivos fundamentales de este trabajo. Desde el momento en que fue elegida para la edificación de una instalación en la que primaron los criterios de ubicación logística sobre los de protección radiológica, la historia y la tragedia de la FUA han sido un estigma para la ciudad de Andújar. Al menos para quienes la han conocido, para los que trabajaron en ella y aún sobreviven ${ }^{2}$ y quieren que se sepa la verdad, sin suposiciones ni especulaciones de carácter político.

\subsection{Las minas de uranio de Cardeña (Córdoba).}

El Parque Natural de las Sierras de Cardeña y Montoro fue declarado como tal no sólo por su riqueza botánica y faunística, sino también por la simbiosis existente entre la actividad humana y el buen mantenimiento de un medio seminatural y antropizado como es el sistema agrosilvopastoril de la dehesa. Sus límites fueron rectificados desde el proyecto original al definitivo $^{3}$, y actualmente ocupa la mayor parte del término municipal de Cardeña y la parte septentrional del de Montoro. Pese a los propósitos de la creación del Parque Natural como yacimiento de nuevos empleos relacionados con el turismo rural y ambiental y el desarrollo sostenible en general, la realidad, al cabo de tres décadas de su creación, paralela a los de la sierra de Andújar y la sierra de Hornachuelos, deja bastante que desear como se deduce de la despoblación de la propia localidad, la atonía socioeconómica de las últimas décadas y la escasez de infraestructuras turístico-recreativas de cierta entidad. Porque, aun habiendo muy loables iniciativas de turismo de interior, cinegético y de naturaleza o activo -aún algunas particularmente inconclusas ${ }^{4}$-, el escaso volumen de población residente en la localidad, así como la escasa demanda turística de esas actividades llevan a convertirlas en un elemento no definitorio de la economía comarcal, cuya situación relativamente marginal con respecto al Valle de Los Pedroches, le otorga una cierta diferencia con el resto de localidades cercanas.

\footnotetext{
${ }^{2}$ En el momento de redacción de este trabajo quedaban, según testimonio de D. José Soto Cepas, presidente de la asociación de ex trabajadores de la FUA, sólo 15 de los 126 trabajadores originales y ninguno de los 9 técnicos (que vivían allí mismo en unos respetables chalets, a apenas 50 metros de la escombrera).

${ }^{3}$ De acuerdo con la documentación recogida en el trabajo de MUÑOZ, J.A., aún inédito, se afirma que: “... si bien en el mismo BOJA $n^{\circ} 60$ del 27 de julio 1989, se da una superficie aproximada de 41.212 hectáreas, actualmente, y una vez puesto en marcha en Plan Rector en 2003, se replanteó esta cifra a la baja, siendo la superficie total del Parque Natural de 38.449 hectáreas que se extienden entre el norte del término municipal de Montoro y la casi totalidad del término municipal de Cardeña."(Vid. Bibliografía). Por tanto, se incluyen las parcelas en las que estuvieron las antiguas minas, que pasaron casi una década sin sellar ni restaurar, pero incluidas en el Parque Natural.

${ }^{4}$ Como es el caso de la Aldea del Cerezo, que está a medio restaurar y no parece tener fecha cierta de apertura después de décadas de actuaciones y proyectos fallidos de rehabilitación y acondicionamiento para complejo turístico rural.
} 


\section{Figura 3}

Ovejas pastando sobre terrenos de la antigua mina de El Cano, la principal mina uranífera de Cardeña.

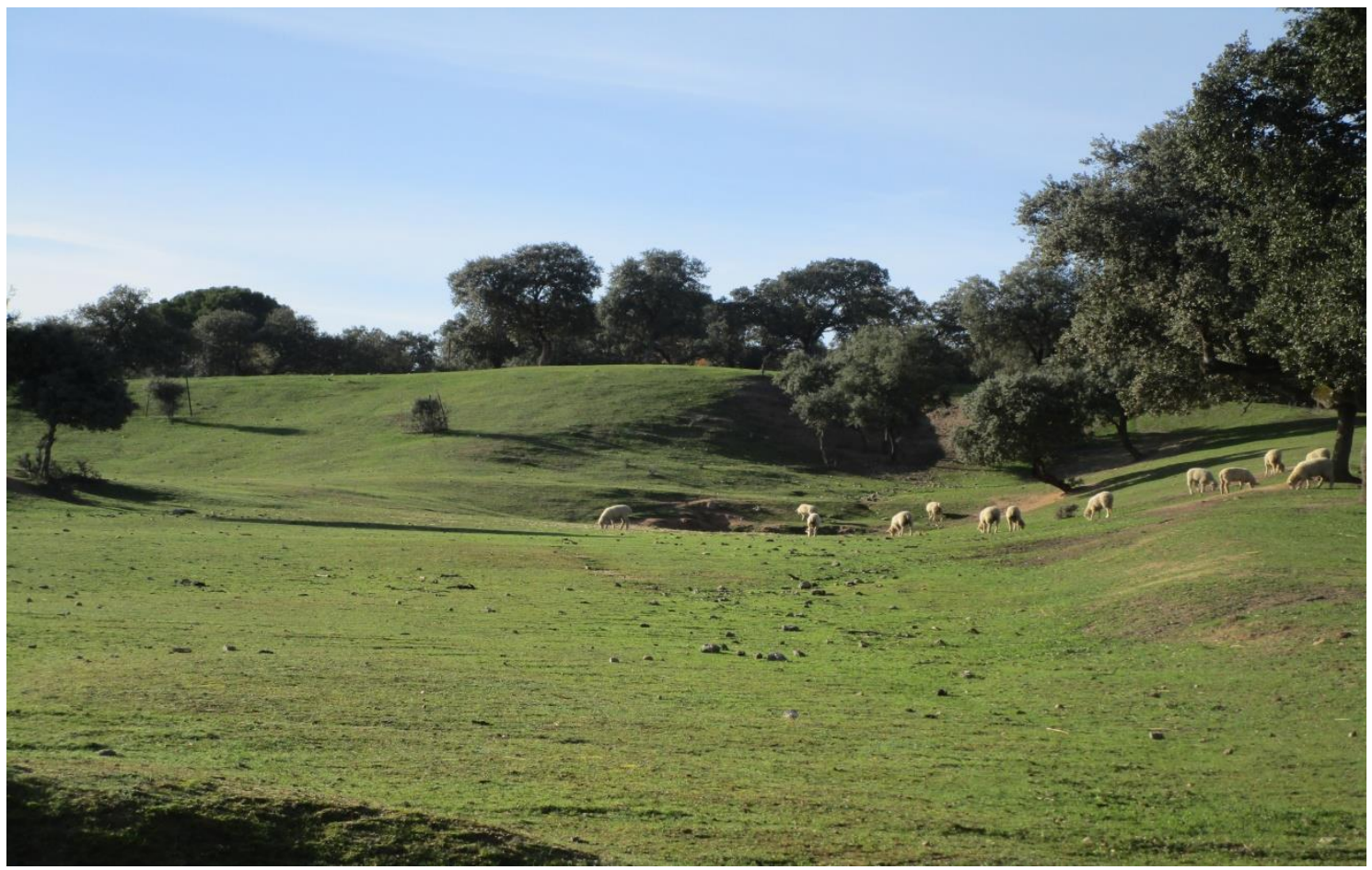

Fuente: Fotografía del autor, diciembre de 2019.

\subsection{El Cabril y Sierra Albarrana (Hornachuelos, Córdoba).}

La Ley-Inventario de Espacios Naturales Protegidos 2/1989 surgió en el momento en el que empezaba a formularse un nuevo concepto de desarrollo sostenible basado parcialmente en la búsqueda de iniciativas de diversificación económica compatibles con la preservación de los espacios naturales protegidos como el turismo rural o de naturaleza basado en el aprovechamiento racional de los recursos territoriales endógenos. La idiosincrasia de la propia ley se identificó enseguida con este nuevo concepto de desarrollo y ello condujo a algunas actuaciones de dotación de equipamientos e infraestructuras en estos nuevos espacios protegidos, tales como Centros de Interpretación, Áreas recreativas, Albergues juveniles, Campings, en su mayor parte de iniciativa pública ante la escasa iniciativa privada existente, por lo demás hiperdependiente de las subvenciones de carácter público. Aún así, algunos equipamientos tales como casas y hoteles rurales, mesones rurales y otros establecimientos relacionados con el ocio y la hostelería, han ido cubriendo las necesidades de una demanda emergente, aunque todavía muy limitada, de actividades de turismo rural, de naturaleza y activo-deportivo. Al cabo de tres décadas largas de vigencia de esta legislación y de las políticas sectoriales conexas, lo cierto es que el fomento de estas nuevas activies adolece de muchas medidas sustantivas que hubieran evitado la excesiva dependencia de las ayudas oficiales, sin las cuales, y cuando han dejado de existir, no se han podido mantener abiertos 
muchos establecimientos de micropymes con escasa profesionalización, recursos humanos y materiales y mínimo conocimiento de la gestión empresarial necesaria para su sostenibilidad ${ }^{5}$.

En realidad, ni siquiera las cuantiosas ayudas de compensación concedidas por la Fundación ENRESA a los municipios del entorno de influencia de El Cabril por los impactos negativos previsibles de la existencia en la zona del mayor cementerio de residuos nucleares de España (Figura 4), han tenido un impacto destacable para el impulso y desarrollo de nuevas actividades productivas ligadas al turismo rural, de naturaleza y activo-deportivo, salvo muy contadas excepciones como la puesta en marcha reciente de un Parque de Aventura en la Naturaleza.

\section{Figura 4}

Vista aérea de las instalaciones del cementerio nuclear de El Cabril, en la Sierra Albarrana

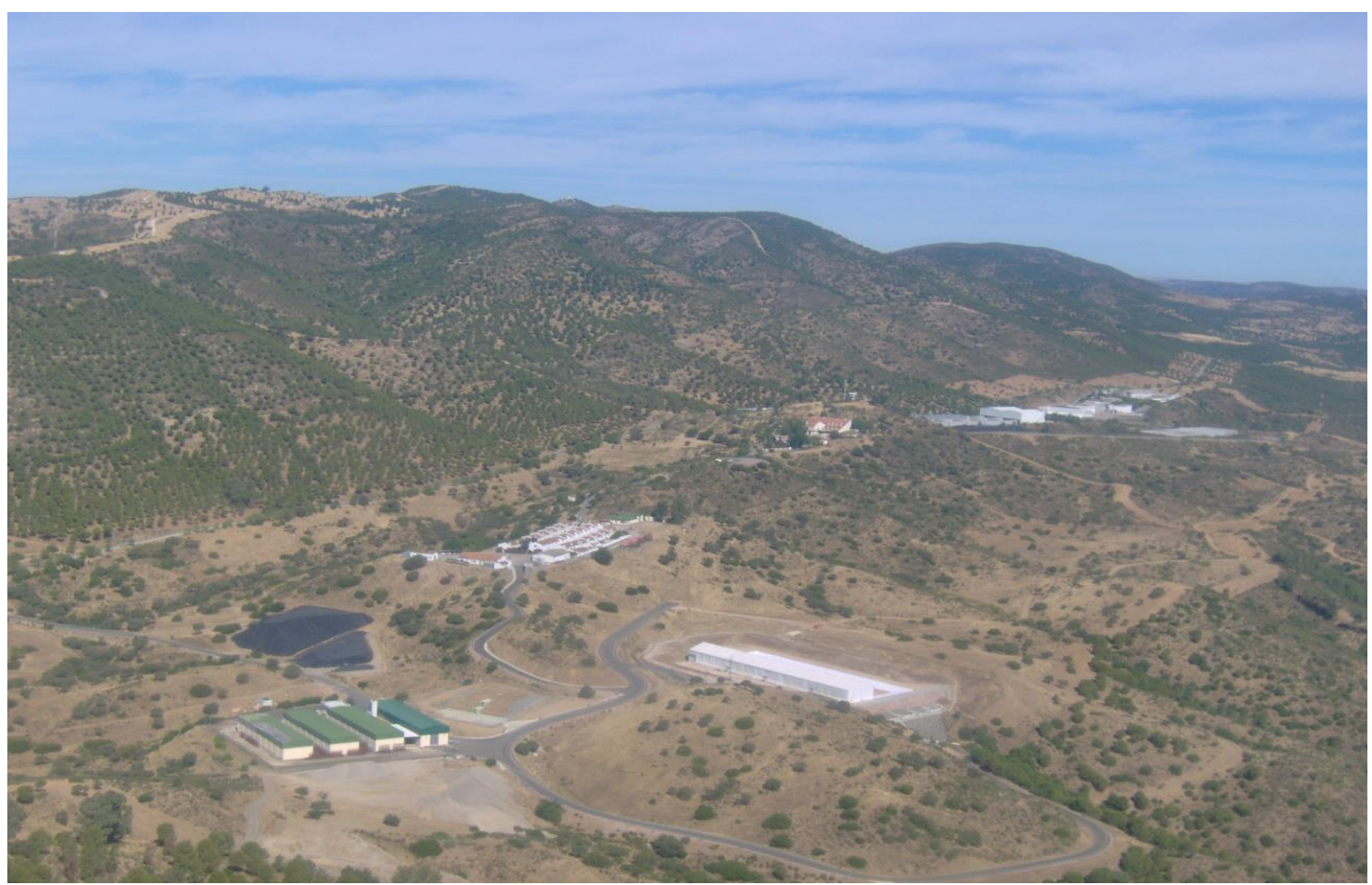

Fuente: Fotografía del autor, tomada desde helicóptero de ENRESA.

Debemos de tener en cuenta en el entorno de las instalaciones del cementerio nuclear, una serie de condicionamientos insoslayables que explican la realidad socioeconómica y también turístico-recreativa de este entorno marginal de la Sierra Morena andaluza:

-En El Cabril, en unos 15 kilómetros a la redonda, no vive nadie de modo permanente, ni tan siquiera en las fincas, salvo algunos guardas que ya no aparecen ni censados en los diseminados que existieron alrededor del Cabril hasta el inicio del presente siglo ${ }^{6}$. El vacío de

\footnotetext{
${ }^{5}$ No hay más que darse una vuelta por la Sierra Norte sevillana y conversar con los lugareños. La palabra "subvención" y "subsidios" aparece con demasiada facilidad tras treinta años desde la creación del Parque Natural, vendido como "panacea" contra su "secular subdesarrollo", sin que en la práctica los cambios socioeconómicos apenas hayan llegado o lo hayan hecho tarde y mal.

${ }^{6}$ A saber, El Alta, al suroeste del Cabril y La Adelfilla al sureste.
} 
poblamiento de la zona y las restricciones de usos y actividades en el área de influencia de El Cabril no favorece el desarrollo de iniciativas de desarrollo.

-El Cabril limita al sur con el límite norte del Parque Natural de la Sierra de Hornachuelos ${ }^{7}$. En este entorno serrano tiene particular importancia el turismo cinegético, particularmente orientado hacia la caza mayor en su modalidad de monterías en los cotos de caza cercados. Tan sólo en las cercanías de la localidad meloja o en el mismo casco urbano se aprecian algunas actividades de carácter turístico-recreativo sustentadas en algunas rutas de senderismo, la celebración de talleres de educación ambiental y las visitas de observación de flora y fauna en el entorno del Centro de Visitantes de Huerta del Rey. La estructura de la propiedad, claramente latifundista y en fincas privadas cercadas a las que no se puede acceder, limita bastante el uso turístico-recreativo.

-La ausencia de infraestructuras y equipamientos turístico-recreativos funcionales tiene mucho que ver con la perificidad geográfica de la zona, la accesibilidad deficiente, el importante éxodo rural y el fuerte envejecimiento de la población y hasta el impacto negativo de la existencia del propio cementario nuclear en el imaginario turístico de la zona, más aún cuando tiene ésta un potencial turístico innegable pero vinculado a su entorno natural, biodiversidad y carácter ambiental. A esto hay que añadir la escasa promoción turística de la comarca y la inexistencia de una planificación efectiva y estratégica de su desarrollo sostenible, ya que no se ha ido más allá de actuaciones aisladas, "a salto de mata", poco meditadas y con una falta de criterios de gestión y viabilidad y/p excesivamente dependientes de la iniciativa pública y las subvenciones y ayudas de las Administraciones Públicas. De hecho, pese a diversos trabajos publicados sobre las importantes potencialidades del Parque $\mathrm{Natural}^{8}$, la situación de depresión socioeconómica tradicional está lejos de superarse y ni tan siquiera se ha sabido aprovechar la declaración oficial de este espacio protegido como Reserva de la Biosfera de la UNESCO "Dehesas de Sierra Morena".

\subsection{Palomares-Sierra Almagrera (Almería).}

La situación es bien distinta en el caso de Palomares, una pedanía del municipio de Cuevas de Almanzora, en Almería. Si bien en teoría no tendría por qué estar dentro de las zonas ligadas al patrimonio nuclear de España, lo cierto es que esta zona se ha tenido que convertir en objeto de estudio de nuestro trabajo habida cuenta de las consecuencias del accidente aéreo-nuclear del 17 de enero de 1966 que tuvo lugar en sus playas, con secuelas aún perceptibles en el parcelario municipal y en el imaginario de la población:

-La zona afectada se encuentra bastante inmediata a la costa, tanto las parcelas contaminadas, expropiadas y sometidas a vigilancia por el Centro de Investigaciones Energéticas, Medioambientales y Tecnológicas del Gobierno de España (CIEMAT) del entorno de la "diputación" (nombre de la pedanía) como de la propia Sierra Almagrera, en la que la "pluma" radiactiva no fue descubierta hasta 2009, momento del levantamiento en 3D del plano de la zona".

\footnotetext{
${ }^{7}$ Es más, el cartel metálico de bienvenida al Parque Natural de la Sierra de Hornachuelos se encuentra apenas se cruza el río Bembézar por el Puente de los Tres Mojones.

${ }^{8}$ Como el libro de MUÑOZ, J.A.: "El Cabril: estudio y artículos geográficos" y los trabajos previos que lo sustentaron.

${ }^{9}$ Fue una orden de la Presidencia del Gobierno español en el momento en el que el gobierno estadounidense planteó recortar la financiación de las labores de vigilancia y descontaminación en 2007.
} 
-Asimismo, se encuentra con una serie de infraestructuras turísticas relativamente desarrolladas y funcionales, tanto vinculadas a las inmediatas playas de Garrucha y Villaricos, como a las antiguas minas de la sierra Almagrera, que son objeto de distintas rutas turísticas interesantes, contando con una demanda turístico-recreativa nada desdeñable.

-La preservación ambiental de niveles aceptables de este entorno de las costas almerienses, por su tardío desarrollo turístico e inmobiliario en relación con el de otras costas como la del Sol o la Costa Blanca, ha favorecido un turismo más ligado a los recursos territoriales y paisajísticos de la zona y su aprovechamiento más sostenible y menos intensivo. Las urbanizaciones y equipamientos surgidos por la proximidad de la playa y otros recursos territorial $^{10}$, como la benignidad del clima y su escasa pluviosidad, está favoreciendo un desarrollo turístico sin parangón con el resto de territorios comprendidos en el patrimonio nuclear del país, ubicados en zonas de interior, de montaña media o piedemonte serrano, que cuentan con mayores condicionamientos negativos para el desarrollo turístico, con una escasa diversificación y dinamización económica y una población fuertemente envejecida, subsidiada y con mínimas expectativas de iniciativa emprendedora.

Aparte del turismo de sol y playa, las rutas de senderismo y de observación del paisaje y el medio natural o las actividades de turismo activo-deportivo ligadas sobre todo al litoral (Rivera, 2011), en las dos últimas décadas se han desarrollado otras posibilidades vinculadas al turismo y la arqueología minero-industriales en el entorno de los antiguos pozos y poblados mineros de la comarca.

Figura 5

Inmediaciones de Villaricos (necrópolis fenicia de Baria). A tan sólo 3 km. de aquí cayó la "pluma" de plutonio de las bombas del accidente de Palomares

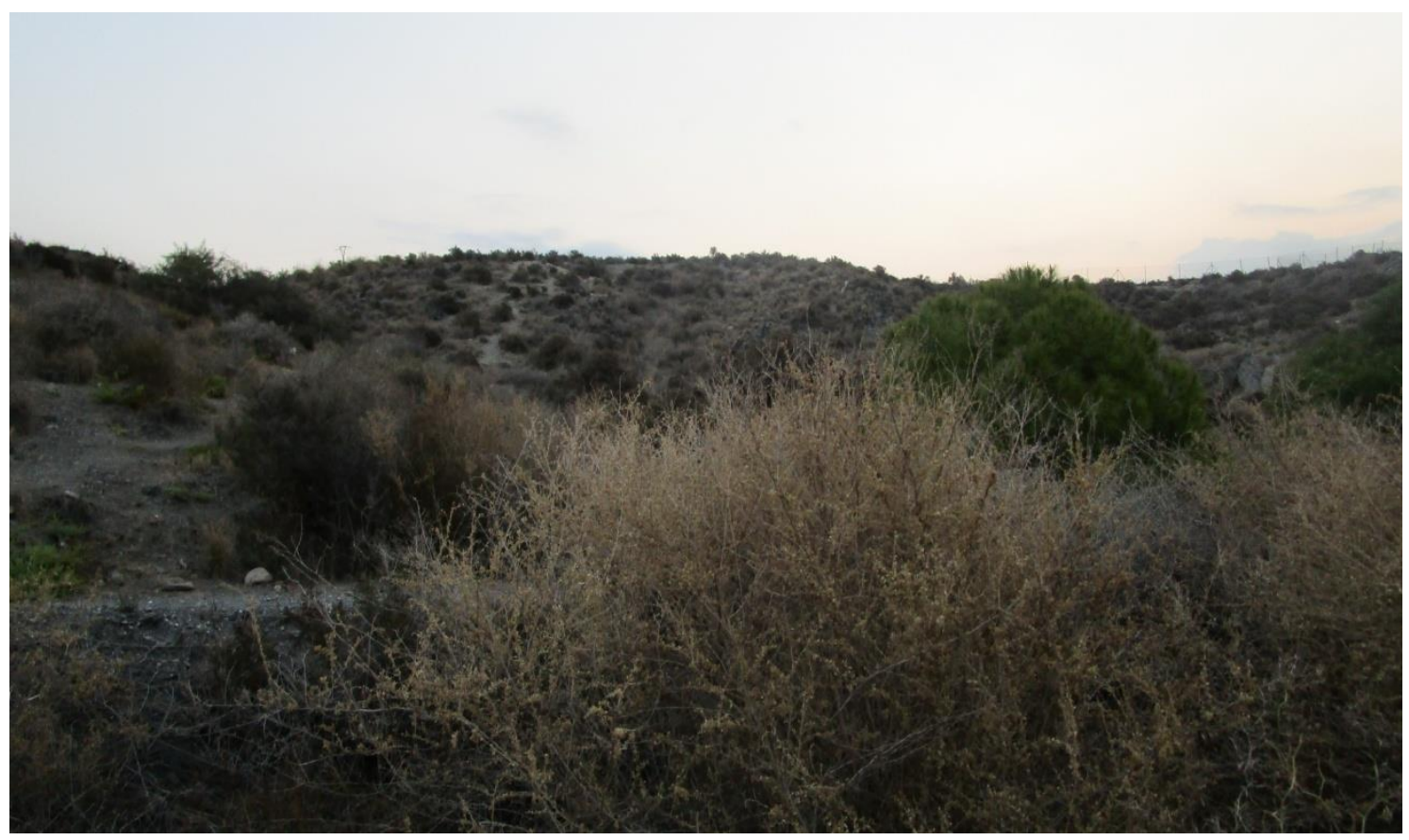

Fuente: Fotografía del autor (septiembre de 2018).

\footnotetext{
${ }^{10}$ Como es el caso del complejo residencial en torno al golf "Desert Springs", entre Las Cunas y Palomares.
} 


\subsection{La Haba-Lobo-Pedregal-Marilozana (Badajoz).}

La Haba, en el límite de las Vegas Altas con la comarca de La Serena ${ }^{11}$, sitas ambas en la provincia de Badajoz, tiene en común con la Sierra de Andújar, Cardeña y Hornachuelos la escasa población y el fuerte éxodo rural, así como su depresión socioeconómica y la crisis de sus actividades agrarias tradicionales que apenas han podido complementarse otras alternativas de desarrollo. Lo mismo podemos decir de la zona inmediata a las antiguas minas de uranio -en particular las del Lobo y el Pedregal-, donde realmente no hay censado nadie en bastantes kilómetros a la redonda, sobre todo en dirección sur, por lo que existe un vacío demográfico ya prácticamente irreversible (Figura 6).

Los servicios de todo tipo, del mismo modo, son escasos. Muchos jabeños, agricultores, ganaderos y guardas de fincas, son empresarios autónomos que tienen un pequeño negocio o se dedican a algunas actividades de transporte particular. Y aún así, la actividad agraria es la dominante en las estadísticas de actividades económicas y quien más, o quien menos, complementa a éstas con algún ingreso complementario en la zona o en los vecinos municipios de Don Benito y Villanueva (de la Serena) ${ }^{12}$, en muchos casos en el ámbito de la economía sumergida e irregular.

Tampoco, desde luego, es un municipio que tenga una especial orientación turística, puesto que sus monumentos de carácter histórico son escasos: la iglesia parroquial de San Juan Bautista, ecléctica e iniciada en el siglo XVI, quedó seriamente dañada durante la Guerra Civil de 1936-39, y en la misma calle Iglesias tan sólo destaca la pequeña capilla neogótica del antiguo convento del Carmen, en la que se encuentra el panteón de los condes de Campos de Orellana, fundadores del mismo. Aún cuando hay algunos edificios solariegos de antiguos hacendados extremeños, que tienen elementos de granito y antiguos blasones, el pueblo carece de un interés monumental y turístico suficiente como para generar una demanda turística significativa ${ }^{13}$.

Sin embargo, su entorno hacia el sur está dominado por dehesas y repoblaciones forestales en las que, aparte de la actividad ganadera y agrícola marginal, hay una notable actividad cinegética, que podría desarrollarse aún más, pero que cuenta, como en otras áreas cinegáticas de la montaña media española, con ciertos hándicaps derivados de una estructura y gestión de la propieda fuertemente latifundista y absentista donde la caza no se explota muchas veces con una orientación económico-empresarial propiamente dicha sino como una actividad de ocio para los propietarios, familiares y amigos sin fines lucrativos.

Otra cosa es que estos cotos de caza puedan implementar potencialmente actividades de turismo cinegético a mayor escala y de clara orientación comercial a través de "empresas orgánicas" e intermediarias, e incluso servir de soporte para el turismo ornitológico, el senderismo u otras actividades recretivas, pero lo cierto es que sus propietarios, por lo general, no se sienten motivados ni necesitados de explotar turísticamente sus propiedades. Y a esto debemos de añadir que el potencial turístico-recreativo de estas zonas queda orillado por el estigma que han supuesto las actividades mineras de extracción de uranio y el imaginario

\footnotetext{
${ }^{11}$ Los escasísimos jabeños que hablaron con el autor de este trabajo durante la realización de labores de campo para su Tesis, en noviembre de 2018.

12 A nuestro entender, creemos que es el único caso análogo a una "conurbación formada por dos agrociudades" del que tenemos noticia en España.

${ }^{13}$ En el entorno inmediato de La Haba, cabría destacar la localidad de Magacela, desde cuya estación de tren hoy abandonada-y bastante fotogénica- se cargaba el mineral de uranio hasta la FUA antes de la creación de la planta "experimental" de ENUSA.
} 
negativo como "área radioactiva y contaminada" que se ha acuñado, particularmente, en la mina La Marilozana, quizás la de mayor índice de radioactividad.

Figura 6.

Zona de la antigua Marilozana, la más peligrosa del yacimiento de La Haba al ser una explotación a cielo abierto

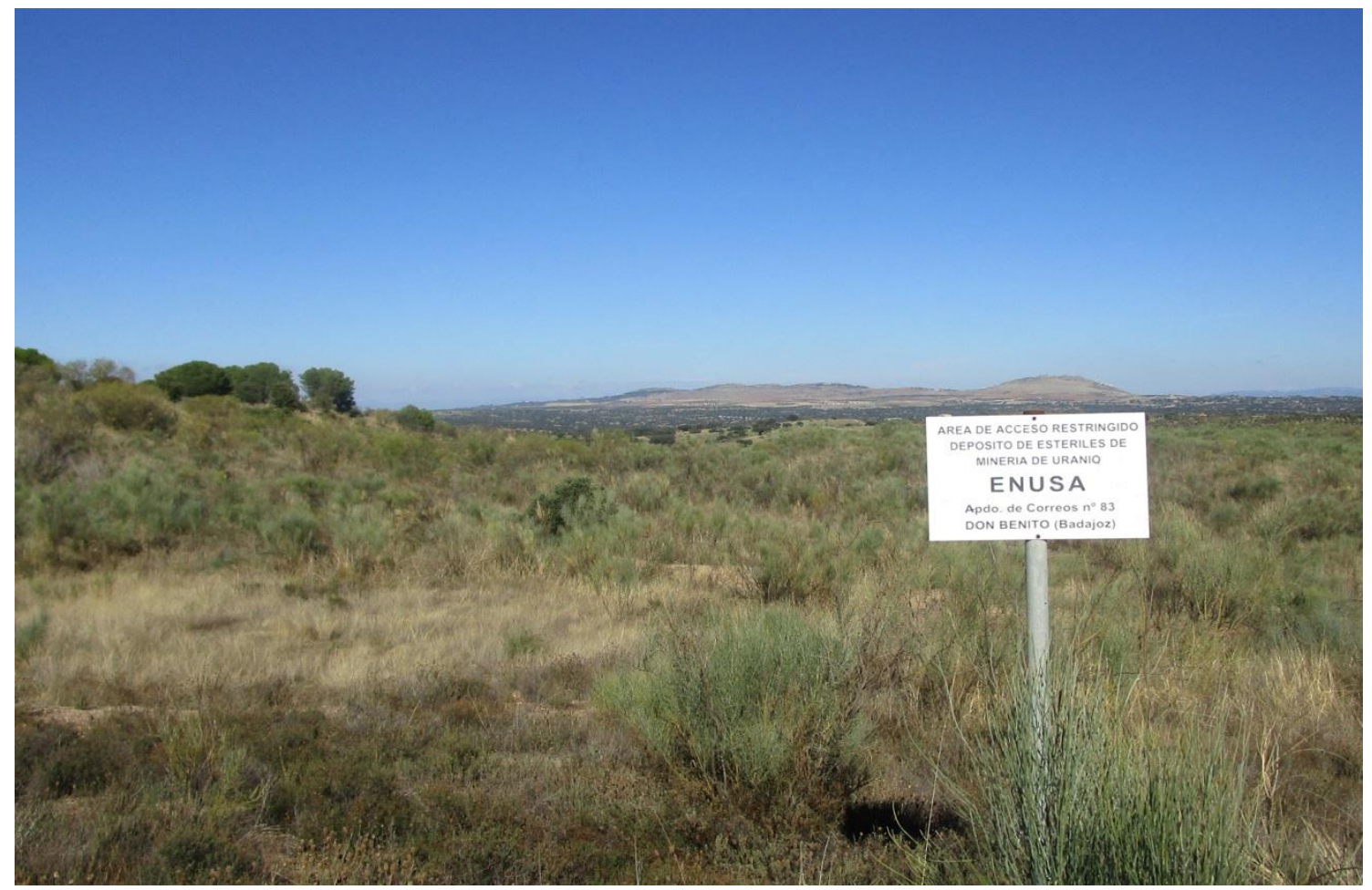

Fuente: Fotografía del autor (noviembre de 2018).

Los indicadores de renta del pueblo son, en cualquier caso, propios de una economía fuertemente deprimida y subsidiada. A saber:

-Renta per cápita por debajo de los 1.000 euros por mes y habitante, con ingresos procedentes en muchos casos de las pensiones.

-Escasa terciarización y diversificación de las actividades productivas.

-Escaso producto interior bruto.

-Bajo nivel educativo general de sus habitantes y mínima iniciativa empresarial.

-Alta emigración, sobre todo de la población más joven.

-Casi nula inmigración.

Estas características se podrían extrapolar a la Sierra de Andújar y se pueden considerar prácticamente comunes a Cardeña, Hornachuelos y el siguiente caso objeto de estudio en nuestro trabajo: el de una remota localidad de la Cuatro Villas al norte de la Siberia Extremeña. 


\subsection{Valdecaballeros (Badajoz).}

Mientras que en La Haba la actividad minera e industrial asociada ha sido considerada la causa directa de una auténtico proceso de decadencia socioeconómica de la localidad por su exposición a la radiactividad del uranio, Valdecaballeros sufrió las consecuencias de la no puesta en marcha de una central nuclear que fue una esperanza truncada del desarrollo local durante más de un cuarto de siglo.

El pueblo en sí tiene un escaso patrimonio inmobiliario tradicional, como se puede comprobar in situ, casi reducido a la iglesia parroquial del siglo XVI y muy reformada después de la Guerra Civil de 1936-1939, así como algunas pocas viviendas hechas con el tapial tradicional y estructuras de piedra. Sin lugar a dudas, el cuarto de siglo de actividades, tanto para la creación y erección de la Central Nuclear como para su posterior desmantelamiento sin haber sido puesta en actividad, dieron lugar a un frenético proceso urbanístico en esta pequeña localidad de las Cuatro Villas de la Siberia Extremeña.

Valdecaballeros es una zona de abundantes recursos hídricos. No sólo por la presencia del pantano de García de Sola, sino porque se encuentra sobre un acuífero ${ }^{14}$ que da un agua de sabor ligeramente plumbífero. No en vano, la localidad cuenta con un cercano balneario, Valdefernando, cerrado finalmente tras algunos años de irregular actividad. Las largas obras de construcción y la tensa espera por la puesta en marcha de la Central Nuclear (Figura 7), dieron lugar en su momento a una expansión inmobiliaria y urbanística paralela con una incipiente actividad hotelera y hostelera para atender a las necesidades de los trabajadores y técnicos que participaron en la construcción de la central.

Ni qué decir tiene que todas esas infraestructuras fueron desapareciendo a medida que se alejaban las esperanzas de apertura de la central, de manera que fueron abandonadas a su suerte $^{15}$. Y las alternativas económicas para el desarrollo de la zona no han ido más allá de algunas iniciativas aisladas en materia de turismo rural en la localidad ${ }^{16}$, pero que aun no estando ésta exenta de atractivos ni de instalaciones de acogida ${ }^{17}$, han sido insuficientes a todas luces para asegurar la recuperación demográfica y económica del municipio de manera ostensible, ni tan siquiera con las actividades cinegéticas, ecuestres, senderistas, piscícolas ${ }^{18} \mathrm{e}$ incluso micológicas que generan un cierto nivel de frecuentación turístico-recreativa en la zona.

Los indicadores de la renta per cápita nos indican que Valdecaballeros, como toda la comarca que lo rodea de la Siberia Extremeña, no deja de ser un municipio con unos índices de subdesarrollo y depresión socioeconómica ciertamente alarmantes, incluso muy por encima de los niveles advertidos en los casos de las sierras de Hornachuelos y Cardeña en la provincia de Córdoba. De aquí que al no haberse puesto en marcha la central nuclear, la situación se haya agravado aún más y hayan caído las expectativas iniciales de que esta instalación hubiera

\footnotetext{
${ }^{14}$ De hecho, durante nuestro trabajo de campo nos encontramos a personas llenando sus garrafas con agua de las distintas fuentes para su propio consumo. Muchos no eran de la localidad ni de las fincas cercanas.

${ }^{15}$ La excepción, parcial y estacional, fueron las urbanizaciones o poblados de Los Encinares y Sierrajara, que tienen moradores "de fin de semana/vacaciones", más algunos jubilados.

${ }^{16}$ Valdecaballeros se encuentra a 35 kilómetros del Real Monasterio de Santa María de Guadalupe, que sí tiene algo más de desarrollo turístico vinculado con periódicas peregrinaciones, aparte su innegable patrimonio cultural histórico-artístico, como santuario principal de Extremadura y, aún más desconocido, con el panteón de algunos reyes de la casa de Trastámara.

${ }^{17}$ Realmente hay algunas casas rurales de auténtico lujo, teniendo en cuenta la valía de la zona en cuanto a las actividades de caza y pesca.

${ }^{18}$ Hay muchos aficionados a la pesca en los embalses, en distintos cotos de pesca con y sin muerte.
} 
actuado de motor de arrastre de otras actividades, incluidas la turística, tanto cinegética como piscícola, ambiental o ligada a la balneoterapia, ahora reducidas a su mínima expresión.

\section{Figura 7}

La inmensa mole de hormigón de la Central non nata de Valdecaballeros, abandonada a su suerte

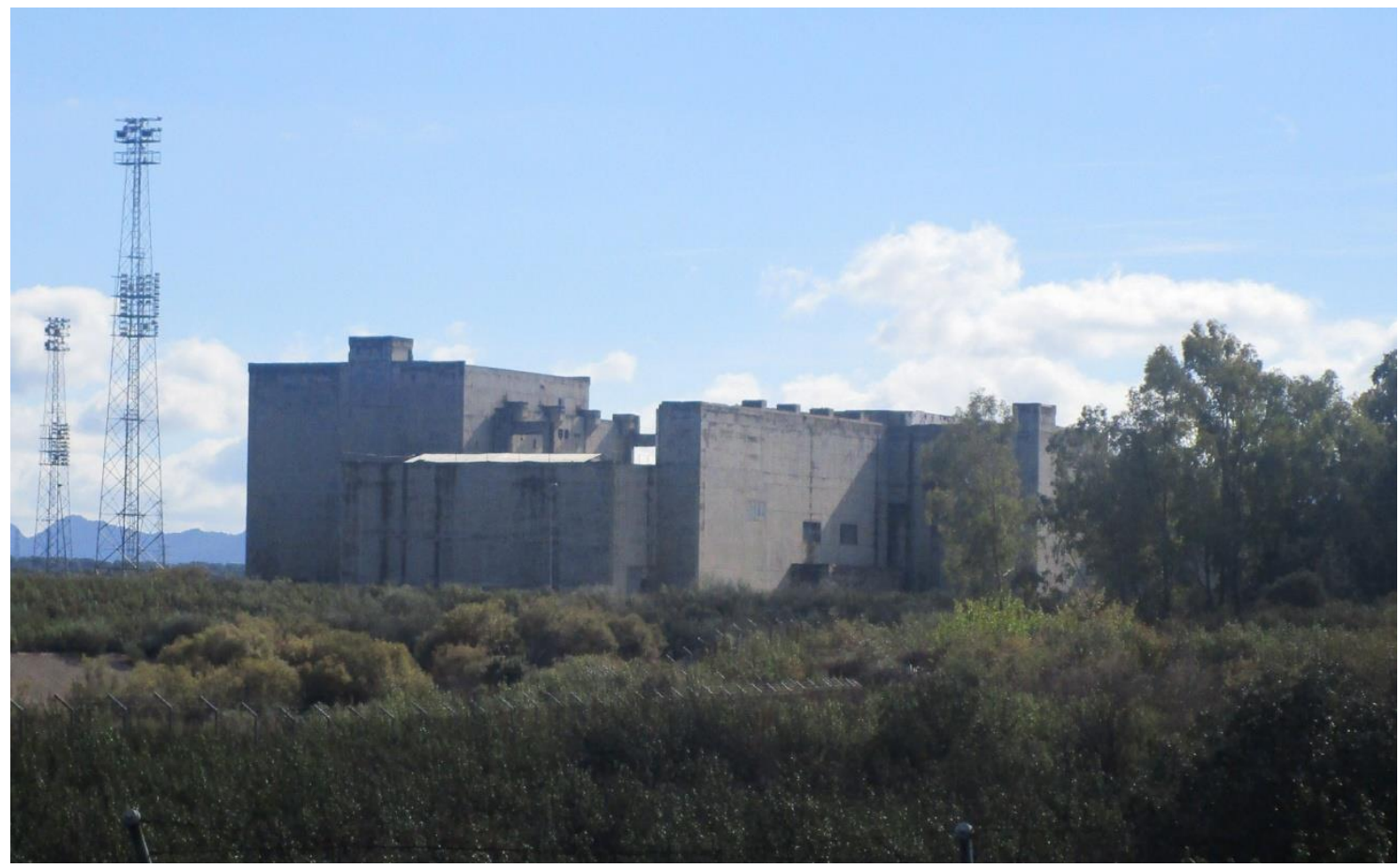

Fuente: Fotografía del autor (noviembre de 2018).

\section{Conclusiones}

La situación de despoblamiento, envejecimiento demográfico y éxodo rural, depresión socioeconómica y crisis de sus actividades tradicionales, además del desmantelamiento de sus instalaciones y estructuras relacionadas con la minería del uranio y la producción de energía nuclear, justifican sobradamente la necesidad de prestar una especial atención a estos territorios tan antológicos de la crisis de la denominada "España vaciada", con la perspectiva de búsqueda de nuevas alternativas de desarrollo económico.

Se puede y se debe hacer mucho más por estas localidades que comparten muchas características comunes, tanto en lo físico, como en lo humano y ni qué decir tiene en lo económico: son localidades básicamente serranas en su práctica totalidad, inmediatas o insertas en espacios naturales protegidos de gran interés patrimonial, ambiental y turístico-recreativo o parajes o zonas húmedas (embalses y cauces fluviales) de gran interés paísajístico y de biodiversidad, pero con problemas severos de escasa renta per cápita y actividades económicas muy por debajo de los niveles de rentabilidad económica y social deseables.

Digamos que la excepción o "verso suelto", valga la expresión, de estos territorios, es Palomares, que cuenta con la ventaja de su proximidad a la costa, lo que le permite tener mejor encauzado un amplio abanico de actividades vinculadas al sector turístico litoral, 
beneficiándose de los flujos turísticos crecientes en este ámbito aún no masificado de la costa almeriense.

Pero la ausencia de iniciativas endógenas y de carácter empresarial-privado es la tónica general de estas áreas, que siguen viviendo en su mayor parte de los subsidios y ayudas públicas y de la asistencia social y, por tanto, inmersas en un círculo vicioso de dependencia y pobreza que conduce incluso a la visión decepcionante, resignada y negativa de sus poblaciones locales acerca de sus perspectivas futuras de desarrollo socioeconómico. Por otro lado, las escasas iniciativas aisladas que se han puesto en marcha en estas zonas en materia de turismo apenas han tenido sostenibilidad, han sido claramente insuficientes como motor de arrastre de las deprimidas economías locales o han dependido excesivamente de las subvenciones públicas o la acción, muchas veces sin criterio y sin viabilidad, de las distintas Administraciones Públicas.

La actuación de la administración se hace, por tanto, francamente necesaria y perentoria, pero ha de redirigirse hacia la puesta en marcha de planes territoriales específicos de desarrollo sostenible, con acciones sustantivas que fomenten la creación de inversiones productivas, el emprendimiento y el impulso de actividades empresariales privadas que se sustenten en la puesta en valor de los nada despreciables recursos territoriales existentes, particularmente $-\mathrm{y}$ como hemos podido identificar- en el ámbito del sector turístico-recreativo, considerando las necesidades de capacitación y profesionalización de los agentes implicados y la puesta en marcha de acciones de promoción y comercialización adecuadas y basadas en la colaboración público-privada.

\section{Referencias}

Chinchilla, M., Gracia, L. (2014). Guía Oficial del Parque Natural de la Sierra de Andújar. Sevilla: Agencia del Medio Ambiente y del Agua y Ed. Almuzara.

Gonzalo Salas, C., Zuaznabar Uzkudun, G., Ródenas, J.F., (2018). Centrales nucleares y Patrimonio: el caso de la central nuclear de Vandellós (Tarragona)", E-rph: Revista electrónica de Patrimonio Histórico, 23, 1-24.

Ivars Baidal, J.A. (2000). Turismo y espacios rurales: conceptos, filosofía y realidades. Investigaciones geográficas, 23, 59-88.

Mulero Mendigorri, A. (2003). Protección y gran propiedad en Sierra Morena: el Parque Natural de la Sierra de Horna chuelos como caso emblemático. Papeles de Geografía, 38, juliodiciembre, 115-136.

Muñoz Castillo, J.A. (2019): El Cabril: estudio y artículos geográficos. Riga: Ed. Académica Española.

Muñoz Castillo, J.A. (2010). El Cabril: un estudio geográfico. Tesina inédita, Universidad de Córdoba (España).

Muños Castillo, J.A. (2017). Patrimonio nuclear del Sur de España: un objeto necesitado de estudio. Revista Argentaria, 14, 94-98.

Muñoz Castillo, J.A. (2020): Patrimonio nuclear del Sur de España: estudio geográfico. Córdoba, tesis doctoral (inédita), Universidad de Alicante.

Prieto, D. y García-Dory, F. (2018): Dominación y (neo)extractivismo. 40 años de Extremadura saqueada. Madrid: Ed. Matadero, col. "Campo Adentro".

Relaño Moyano, J., Pareja Cano, G.(2010). Guía Oficial del Parque Natural de la Sierra de Cardeña y Montoro. Córdoba: Ed. EGMASA y Ed. Almuzara. 
Rengifo Gallego, J.I.: (2008). Un segmento del turismo internacional en auge: el turismo de caza. Cuadernos de Turismo, 22, 187-210.

Rivera Mateos, M. (1992). Explotación agraria y organización de espacio productivo en Sierra Morena. Córdoba: Servicio de Publicaciones de la Universidad.

Rivera Mateos, M. (2007). La emergencia del turismo y el ocio deportivo de naturaleza en Andalucía y España: aproximación al estudio de su demanda reciente. En Turismo y sociedad en Andalucía: recopilación de las comunicaciones presentadas a las I Jornadas sobre Turismo y Sociedad en Andalucía (Rodríguez, P.; Ciria, R.; Moreira, P.E., coord..). Sevilla: Consejería de Turismo, Comercio y Deporte e IESA-CSIC.

Rivera Mateos, M. (2010): Turismo activo en la naturaleza y espacios de ocio en Andalucía: aspectos territoriales, políticas públicas y estrategias de planificación. Sevilla: Consejería de Turismo, Comercio y Deporte.

Rivera Mateos, M. (2011). Los espacios de ocio deportivo de naturaleza en destinos litorales: innovación espacial, nuevas prácticas y cualificación de sistemas turísticos en la costa andaluza. En López Olivares, D. (coord..). Renovación de destinos turísticos consolidados (pp. 701-742). Castellón, Universidad Jaume I y Tirant lo Blanch.

Rivera Mateos, M. (2015): El tratamiento de las actividades de turismo activo en los instrumentos de planificación ambiental de los parques naturales andaluces. Revista de Estudios Regionales, 102, enero-abril, 17-63.

Roldán, J.D. et al. (2017). El perfil del turista cinegético: un estudio de caso para Córdoba (España). International Journal of Scientific Management and Tourism, 3-4, 187-203.

Terstch, H. (2001). Valdecaballeros, la central del nunca jamás. El País, 7 de enero de 2001.

Utrera Cardeñas, P. (2009). El sueño de Franco y la pesadilla de Andújar. Los damnificados de la FUA. Andújar: Ed. Plaza Vieja.

Velarde, G., Carpintero, N. (2016). Proyecto Islero. Cuando España pudo desarrollar armas nucleares. Córdoba: Ed. Guadalmazán (Grupo Almuzara). 